\title{
Reduced Anxiety, Conditioned Fear, and Hippocampal Long-Term Potentiation in Transient Receptor Potential Vanilloid Type 1 Receptor-Deficient Mice
}

\author{
Rudolph Marsch, ${ }^{1}$ Elisabeth Foeller, ${ }^{2}$ Gerhard Rammes ${ }^{1,3}$ Mirjam Bunck, ${ }^{1}$ Manfred Kössl, ${ }^{2}$ Florian Holsboer, ${ }^{1}$ \\ Walter Zieglgänsberger, ${ }^{1}$ Rainer Landgraf, ${ }^{1}$ Beat Lutz, ${ }^{1,4}$ and Carsten T. Wotjak ${ }^{1}$ \\ ${ }^{1}$ Max Planck Institute of Psychiatry, D-80804 Munich, Germany, and 2Johann Wolfgang Goethe University, D-60323 Frankfurt/Main, Germany, \\ ${ }^{3}$ Department of Anaesthesiology, Technical University, D-81675 Munich, Germany, and ${ }^{4}$ Johannes Gutenberg University, D-55099 Mainz, Germany
}

\begin{abstract}
The transient receptor potential vanilloid type 1 channel (TRPV1) (formerly called vanilloid receptor VR1) is known for its key role of functions in sensory nerves such as perception of inflammatory and thermal pain. Much less is known about the physiological significance of the TRPV1 expression in the brain. Here we demonstrate that TRPV1 knock-out mice (TRPV1-KO) show less anxiety-related behavior in the light- dark test and in the elevated plus maze than their wild-type littermates with no differences in locomotion. Furthermore, TRPV1-KO mice showed less freezing to a tone after auditory fear conditioning and stress sensitization. This reduction of conditioned and sensitized fear could not be explained by alterations in nociception. Also, tone perception per se was unaffected, as revealed by determination of auditory thresholds through auditory brainstem responses and distortion-product otoacoustic emissions. TRPV1-KO showed also less contextual fear if assessed $1 \mathrm{~d}$ or 1 month after strong conditioning protocols. These impairments in hippocampusdependent learning were mirrored by a decrease in long-term potentiation in the Schaffer collateral-commissural pathway to CA1 hippocampal neurons. Our data provide first evidence for fear-promoting effects of TRPV1 with respect to both innate and conditioned fear and for a decisive role of this receptor in synaptic plasticity.
\end{abstract}

Key words: memory; learning; fear conditioning; endocannabinoids; LTP; endovanilloids

\section{Introduction}

The transient receptor potential vanilloid type 1 channel (TRPV1) (formerly vanilloid receptor VR1) (for review, see Szallasi and Blumberg, 1999) belongs to a large family of calciumpermeable cation channels (Caterina et al., 1997). In the peripheral nervous system, it is activated by thermal and chemical noxes and by capsaicin (8-methyl- $N$-vanillyl-6-nonenamide), the pungent ingredient of red hot chili peppers. TRPV1 is a polymodal signal detector and can be activated by heat and protons (Tominaga et al., 1998). Synthetic TRPV1 agonists show potent analgesic effects because they initiate rapid receptor desensitization (Szallasi and Appendino, 2004). Accordingly, TRPV1 knock-out mice (TRPV1-KO) were impaired in nociception and showed reduced sensitivity to painful heat in behavioral tests (Caterina et al., 2000). In the CNS, TRPV1 is expressed in various brain areas, including substantia nigra, basal ganglia, hippocampal formation, locus ceruleus, and cortex (Mezey et al., 2000; Roberts et al.,

Received Aug. 1, 2006; revised 0ct. 30, 2006; accepted Nov. 17, 2006.

This study was supported by VolkswagenStiftung Grants I/78560 (B.L.) and I/78562 (C.T.W.). We thank Dr. Heike Blaudzun, Anna Mederer, Christine Hilf, Martina Reents, Carola Hetzel, and Kornelia Kamprath (Max Planck Institute of Psychiatry) for their help with technical support, behavioral analysis, breeding, genotyping of the animals, and valuable comments on this manuscript.

Correspondence should be addressed to C. T. Wotjak, Max Planck Institute of Psychiatry, Kraepelinstrasse 2, D-80804 Munich, Germany. E-mail address: wotjak@mpipsykl.mpg.de.

D01:10.1523/JNEUROSCI.3303-06.2007

Copyright $\odot 2007$ Society for Neuroscience $\quad$ 0270-6474/07/270832-08\$15.00/0
2004; Cristino et al., 2006). Recently, several endogenous ligands of TRPV1 could be characterized (for review, see De Petrocellis and Di Marzo, 2005). On closer examination of these intracerebral "endovanilloids," three different classes of lipids emerged: (1) anandamide, (2) lipoxygenase products of arachidonic acid, and (3) long-chain, linear fatty acid dopamines [e.g., $\mathrm{N}$-arachidonyl-dopamine (NADA)]. Two of these "endovanilloids," anandamide and NADA, are also members of the endocannabinoid family, because they bind to the cannabinoid receptor type $1\left(\mathrm{CB}_{1}\right)$ as well (Zygmunt et al., 1999; Huang et al., 2002). Both TRPV1 and $\mathrm{CB}_{1}$ are colocalized within several brain structures, including the hippocampal formation, in which they can be found in close vicinity at the cellular level (Cristino et al., 2006), with $\mathrm{CB}_{1}$ being expressed primarily in axon terminals (Wilson and Nicoll, 2002) and TRPV1 in postsynaptic dendritic spines and cell somata (Toth et al., 2005). Activation of $\mathrm{CB}_{1}$ usually leads to a decrease in intracellular calcium in presynaptic terminals (Mackie and Hille, 1992) and, thereby, to a reduced transmitter release (Freund et al., 2003). Activation of TRPV1 by anandamide, in contrast, promotes $\mathrm{Ca}^{2+}$ influx in postsynaptic sites (van der Stelt et al., 2005). These observations led to the hypothesis that TRPV 1 and $\mathrm{CB}_{1}$ might exert opposite effects on certain brain functions, including emotionality, cognition, and synaptic plasticity (Di Marzo et al., 2001a; Cristino et al., 2006). However, whereas the physiological relevance of intracerebral $\mathrm{CB}_{1}$ starts to emerge (for review, see Piomelli, 2003; Valverde et 
al., 2005; Wotjak, 2005; Chevaleyre et al., 2006), very little is known about the physiological roles of TRPV1 in the brain. Therefore, we used TRPV1-deficient mice (TRPV1-KO) (Caterina et al., 2000) and their wild-type littermates (TRPV1-WT) to study the relevance of endovanilloid action via TRPV1 on anxiety-related behavior, unconditioned/conditioned fear, and synaptic plasticity.

\section{Materials and Methods \\ Subjects}

TRPV1-deficient mice (TRPV1-KO) (Caterina et al., 2000) were obtained from The Jackson Laboratory (Bar Harbor, ME) and maintained as a heterozygous breeding colony after backcrossing to $\mathrm{C} 57 \mathrm{BL} / 6 \mathrm{NCrl}$ (Charles River Germany, Bad Sulzfeld, Germany) for five generations. The breeding was performed at the Max Planck Institute of Psychiatry. Animals were genotyped by PCR essentially as described previously (Massa et al., 2006). Only male TRPV1-KO and TRPV1-WT were used for experiments at the age of 10-14 weeks. Animals were housed singly with food and water ad libitum under an inverse $12 \mathrm{~h}$ light/dark cycle (lights off, 9:00 A.M.) for at least $14 \mathrm{~d}$ before starting the experiments. All experiments were approved by the Committee on Animal Health and Care of the State of Bavaria (Regierung von Oberbayern, Germany) and performed in strict compliance with the European Economic Community recommendations for the care and use of laboratory animals. All behavioral experiments were performed with different batches of animals during the activity phase of the mice between 9:30 A.M. and 5:00 P.M., unaware of the genotype.

\section{Open field}

To assess general motor activity, TRPV1-WT and TRPV1-KO were tested in an open field $(26 \times 26 \times 38 \mathrm{~cm})$ equipped with infrared beams (TrueScan; Coulbourn Instruments, Allentown, PA) (Siegmund et al., 2005) at 0 lux for $15 \mathrm{~min}$ (for additional details, see next paragraph). Horizontal locomotion (total distance moved), vertical movements (exploratory rearings), and time spent at rest were analyzed in $3 \mathrm{~min}$ intervals.

\section{Light-dark avoidance task}

Mice were tested in the light-dark tests under 350 lux in boxes (Coulbourn Instruments) that were divided into two equally sized compartments $(13 \times 26 \times 38 \mathrm{~cm})$. The light compartment had three transparent Plexiglas walls. The non-illuminated black compartment consisted of black plastic walls, and the roof and floor were painted black. The two compartments were connected by a $7.5 \times 7.5 \mathrm{~cm}$ doorway. Two infrared sensor rings (sensor spacing, $1.52 \mathrm{~cm}$ ) around the boxes allowed the measurement of horizontal and vertical activity. Both sensor rings were connected via interface to a computer equipped with TruScan Software Version 99 (Coulbourn Instruments). Boxes and sensor rings were surrounded by an additional box made of opaque Plexiglas side walls $(47 \times$ $47 \times 38 \mathrm{~cm}$ ) without roof and floor. Compartments and floor were thoroughly cleaned with soap and water between sessions.

Mice were placed into the middle of the dark compartment at the start of the experiment. All three-dimensional movements were automatically recorded over a course of $30 \mathrm{~min}$. The following behavioral parameters were automatically recorded: (1) horizontal locomotion, (2) vertical movements, (3) relative time spent in the light compartment, and (4) relative distance moved in light compartment normalized to the total distance moved. Data were analyzed in 3 min intervals.

\section{Elevated plus maze}

The elevated plus maze was made out of dark gray PVC and consisted of a plus-shaped platform elevated $40 \mathrm{~cm}$ above the floor, with two open $(30 \times 5 \mathrm{~cm})$ and two closed $(30 \times 5 \times 15 \mathrm{~cm})$ arms and a connecting central zone $(5 \times 5 \mathrm{~cm})$. The open arms were lit by white light of 300 lux, the neutral zone by 115 lux, and the closed arms by 5 lux. The test was performed between 10:00 A.M. and 12:00 A.M. Animals were kept in the test room for $24 \mathrm{~h}$ before starting the experiment. They were placed onto the central compartment facing the closed arm. During a 5 min exposure, the following parameters were recorded/calculated by an experienced observer by means of a video/computer system (Plus-maze version 2.0; Ernst Fricke, Germany, 1993) as described by Kromer et al. (2005): (1) the number of entries into open and closed arms, (2) percentage of entries into open arms (ratio of open-arms entries to sum of entries into all arms), and (3) the relative time on the open arms.

Fear conditioning, sensitization, and unconditioned fear to a tone Experiments were performed in two contexts: (1) the conditioning chamber and (2) the test context, which differed in various aspects, including shape, odor, illumination, and bedding (for details, see Kamprath and Wotjak, 2004). Contexts were cleaned thoroughly after each trial, and the bedding was changed. For auditory fear conditioning, animals were placed in the conditioning chamber. After $3 \mathrm{~min}$, a tone $(9$ $\mathrm{kHz}, 80 \mathrm{~dB}$ sine wave) was presented for $20 \mathrm{~s}$ that coterminated with a single scrambled electric footshock $(0.70 \mathrm{~mA}, 2 \mathrm{~s})$ administered via the metal grid.

For stress sensitization, mice were placed into the conditioning chamber and exposed to three $1 \mathrm{~s}$ footshocks $(0.7 \mathrm{~mA}$; administered 198, 308, and $448 \mathrm{~s}$ after insertion into the chamber) or one $2 \mathrm{~s}$ footshock ( 0.70 or $1.5 \mathrm{~mA}$; administered $198 \mathrm{~s}$ after insertion into the chamber), as described above, except that the tone presentation was omitted. In any case, mice remained in the chamber for additional $60 \mathrm{~s}$ after the last shock before they were returned to their home cages.

To analyze freezing to the tone, mice were habituated to the neutral test context for $3 \mathrm{~min}$ and then exposed to a $3 \mathrm{~min}$ tone $(9 \mathrm{kHz}, 80 \mathrm{~dB}) 1$ and $7 \mathrm{~d}$ after conditioning and sensitization, respectively. After tone presentation, animals remained in the test context for another $60 \mathrm{~s}$ before they had been returned to their home cages.

To test for unconditioned fear to a tone, naive mice were exposed to a loud tone $(9 \mathrm{kHz}, 95 \mathrm{~dB})$ of $3 \mathrm{~min}$ duration that was activated $3 \mathrm{~min}$ after the animals were placed into the test context at days 1 and 7 .

For measuring contextual fear memory, mice that had been subjected to auditory fear conditioning or sensitization procedures were exposed to the conditioning chamber $1 \mathrm{~d}$ later for $3 \mathrm{~min}$. For measuring long-lasting contextual memory, an additional batch of mice was placed into the conditioning chamber, in which the animals received a $1.5 \mathrm{~mA}$ footshock (see above), and reexposed to the conditioning chamber $28 \mathrm{~d}$ later for 3 min.

Unconditioned, conditioned, and sensitized fear were assessed off-line from video tapes by an experienced observer who quantified the freezing response to the tone and the conditioning context, respectively (for details, see Kamprath and Wotjak, 2004).

\section{Pain threshold}

Each animal was placed individually in the conditioning chamber. After $180 \mathrm{~s}$, the electric current was gradually increased by hand at a rate of 5 $\mu \mathrm{A} / \mathrm{s}$ until the animal showed the first signs of discomfort (moving backwards and flicking with the hindlegs) and pain (jumping and vocalization). At this moment, the current was immediately switched off, and the respective current was taken as a measure of the animal's discomfort/ pain threshold.

\section{Recording of distortion-product otoacoustic emissions}

Mice were anesthetized with a mixture of ketamine/xylazine and placed on a controlled heating pad in a soundproof chamber. The animal's head was fixed with a mouth holder. Distortion-product otoacoustic emission (DPOAE) threshold curves were measured as described previously (Wittekindt et al., 2005). Briefly, a closed coupler system, containing two microphones (model 4133, 1/2 inch; Brüel and Kjær, Norcross, GA) used as loudspeakers and one recording microphone (model 4135, 1/4 inch; Brüel and Kjær), was positioned in the meatus close to the eardrum. Two pure-tone stimuli $\left(2 \mathrm{f}_{1}-\mathrm{f}_{2}\right)$ were generated by a data acquisition board (DAB 3200; Microstar, Bellevue, WA), attenuated, and sent to the speakers after amplification. The speakers were calibrated in situ. The $2 \mathrm{f}_{1}-\mathrm{f}_{2}$ DPAOEs were recorded by the microphone, amplified (model 2610; Brüel and Kjær), and fed to the analog-to-digital input of the DAB board. The $2 f_{1}-f_{2}$ threshold curves were measured for $f_{2}$ frequencies from 6 to 40 $\mathrm{kHz}$ (12 values). By keeping $\mathrm{f}_{2}$ constant and varying $\mathrm{f}_{1}$, the optimum stimulus separation was determined, which produced maximum $2 f_{1}-f_{2}$ levels at low stimulus levels. Growth functions of the $2 \mathrm{f}_{1}-\mathrm{f}_{2}$ distortion 
were measured by increasing the stimulus levels in $5 \mathrm{~dB}$ intervals. The level of $f_{2}$ sufficient to evoke a $2 f_{1}-f_{2}$ of $-10 \mathrm{~dB}$ sound pressure level (SPL) was defined as threshold criterion. Experiments and analysis were performed blind to the animals' genotype.

\section{Recording of auditory brainstem responses}

Mice were anesthetized and kept warm as described above. Incisions of the skin were made above the inferior colliculus (IC) and just behind the caudal base of the pinna. A wire pellet was placed on the skull above the $\mathrm{IC}$, used as the indifferent electrode. A chlorided $\mathrm{AgCl}$ wire was placed close to the skull behind the pinna, next to the meatus. Ground electrode was connected to the skin at the neck. After preamplification (x10), auditory brainstem responses (ABRs) were amplified (1000×), filtered $(0.5-3 \mathrm{kHz})$, and stored in a computer. Stimuli $(10 \mathrm{~ms})$ were presented by the calibrated closed sound system used in DPOAE recordings. ABR threshold curves were measured for frequencies from 6 to $40 \mathrm{kHz}$ (14 different values). Pure tones were increased in level in $2.5 \mathrm{~dB}$ intervals. The ABR patterns were compared off-line, and the lowest intensity at which an $A B R$ pattern could be recognized was determined as the threshold. Threshold was defined as the lowest stimulus level that evoked an ABR above noise level. Experiments and analysis were performed with the same mice used for DPOAE recordings.

\section{In vitro electrophysiology}

Brain slice preparation. Transverse hippocampal slices $(350 \mu \mathrm{m})$ were obtained from adult mice ( 2 months, $n=4$ for both TRPV1-KO and TRPV1-WT mice with one to two slices per animal, resulting in $n=6$ per genotype). All slices were placed in a holding chamber for at least $60 \mathrm{~min}$ and were then transferred to a superfusing chamber for extracellular or whole-cell recordings. The flow rate of the superfusing solution through the chamber was $1.5 \mathrm{ml} / \mathrm{min}$. The composition of the solution was as follows (in mM): $124 \mathrm{NaCl}, 3 \mathrm{KCl}, 26 \mathrm{NaHCO}_{3}, 2 \mathrm{CaCl}_{2}, 1 \mathrm{MgSO}_{4}, 10$ D-glucose, and $1.25 \mathrm{NaH}_{2} \mathrm{PO}_{4}$, pH 7.3 (bubbled with a 95\% $\mathrm{O}_{2}-5 \% \mathrm{CO}_{2}$ mixture). All experiments were performed at room temperature.

Electrophysiological recording. Extracellular recordings of field EPSPs (fEPSPs) were obtained from stratum radiatum of the CA1 region of the dorsal hippocampus using glass micropipettes (1-2 M $\Omega$ ) filled with superfusion solution. For long-term potentiation (LTP) induction, highfrequency stimulation (HFS) conditioning pulses (100 Hz/1 s) were applied to the Schaffer collateral-commissural pathway. We used a stimulation current of $50 \%$ of the maximal response for baseline recordings and HFS, respectively. Measurements of the slope of the fEPSP were taken between 20 and $80 \%$ of the peak amplitude. Slopes of fEPSPs were normalized with respect to the $30 \mathrm{~min}$ control period before tetanic stimulation. fEPSPs were evoked by stimuli $(0.033 \mathrm{~Hz}, 4-5 \mathrm{~V}, 20 \mu \mathrm{s})$, delivered via two bipolar tungsten electrodes insulated to the tip $(5 \mu \mathrm{m}$ tip diameter) and positioned in the Schaffer collateral-commissural pathway. The recordings were amplified, low-pass filtered $(3 \mathrm{kHz})$, and digitized $(9 \mathrm{kHz})$. The digitized responses were stored to disk on a Macintosh computer (Apple Computers, San Jose, CA) using a data acquisition program (for more details, see Simon et al., 2001).

\section{Statistical analysis and data presentation}

Data were analyzed by $t$ test or two-way ANOVA for repeated measurements, followed by Newman-Keuls post hoc test, as indicated in the text. Within-factor effects were Greenhouse-Geisser-adjusted if $p$ was below 0.20 in Mauchley testing. Data are presented as mean \pm SEM. Statistical significance was accepted if $p \leq 0.05$.

\section{Results}

\section{Open field}

To test for general differences in locomotion, we exposed TRPV1-KO and TRPV1-WT to an open field for 15 min under 0 lux. Analysis of the total distance moved failed to reveal significant genotype differences (interval, $F_{(4,68)}=15.0, p<0.001$; genotype, $F_{(1,17)}=1.9, p=0.188$; genotype $\times$ interval, $F_{(4,68)}=$ $1.4, p=0.230)($ Fig. $1 A)$. The same was the case for the number of vertical movements (interval, $F_{(4,68)}=3.7, p=0.008$; genotype, $F_{(1,17)}=0.6, p=0.804$; genotype $\times$ interval, $F_{(4,68)}=1.4, p=$

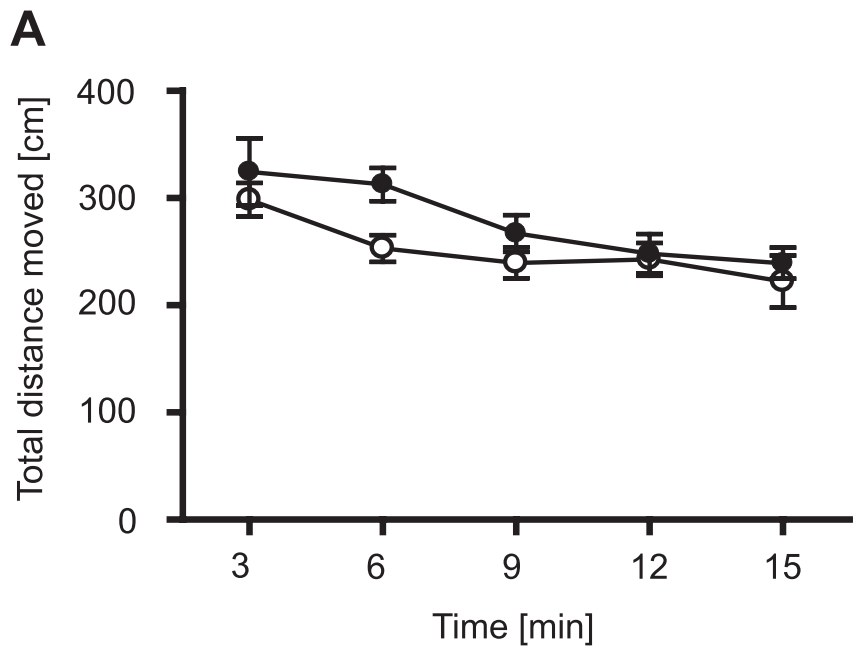

B

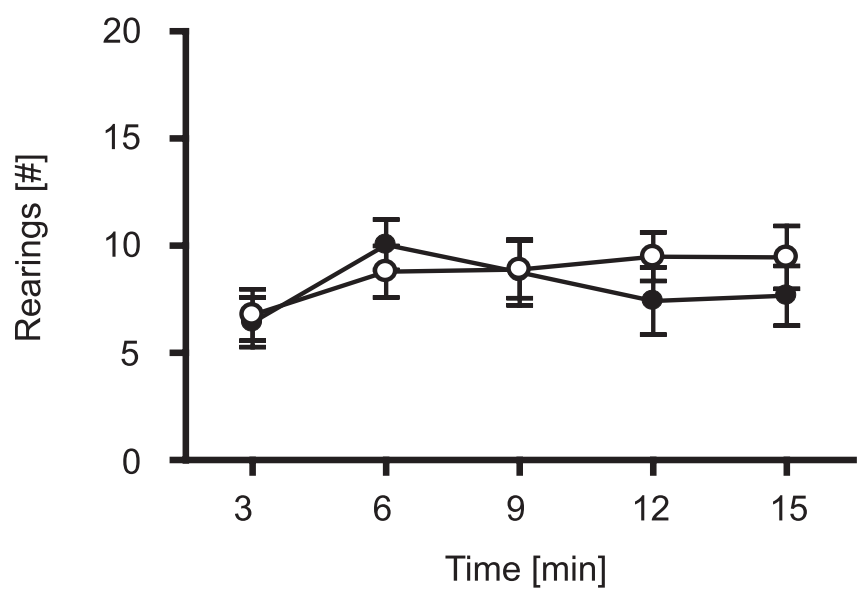

Figure 1. Open field. To test for general differences in locomotion, TRPV1-K0 and TRPV1-WT were exposed to an open field for 15 min under 0 lux. There were no significant differences in horizontal locomotion $(\boldsymbol{A})$ and vertical movements (rearings) (B) between TRPV1-KO (filled circles; $n=7$ ) and TRPV1-WT (open circles; $n=13$ ). Data were analyzed in 3 min intervals.

0.327) (Fig. $1 B$ ), as well as the time TRPV1-KO and TRPV1-WT spent at rest during the entire exposure $(314 \pm 19$ vs $346 \pm 15 \mathrm{~s}$; $\left.t_{(18)}=1.25 ; p=0.23\right)$. Together, these data indicate that both genotypes showed no differences in general locomotion and habituated similarly well to the open field.

\section{Light-dark test}

To assess consequences of TRPV1 deficiency on anxiety-related behavior, we tested TRPV1-KO and TRPV1-WT in a light-dark test. There was no difference between the two genotypes for the total distance moved (genotype, $F_{(1,10)}=0.87, p=0.373$; genotype $\times$ interval, $F_{(9,90)}=1.2, p=0.110$ ) (Fig. $2 A$ ), which is consistent to the results from the open-field test (see above). In contrast, there was a significant genotype difference for the relative distance moved in the light compartment (genotype, $F_{(1,10)}=$ $7.4, p=0.022$; genotype $\times$ interval, $\left.F_{(9,90)}=0.72, p=0.694\right)$, indicating the fact that TRPV1-KO explored the light compartment significantly more than TRPV1-WT (Fig. 2B). Interestingly, whereas TRPV1-KO showed an increase in exploration of the light compartment with ongoing exposure to reach chance levels $(50 \%)$ within $15 \mathrm{~min}$ (interval, $F_{(9,54)}=2.4, p=0.022$ ), TRPV1-WT failed to do so $\left(F_{(9,36)}=0.77, p=0.643\right)$. Analysis of 


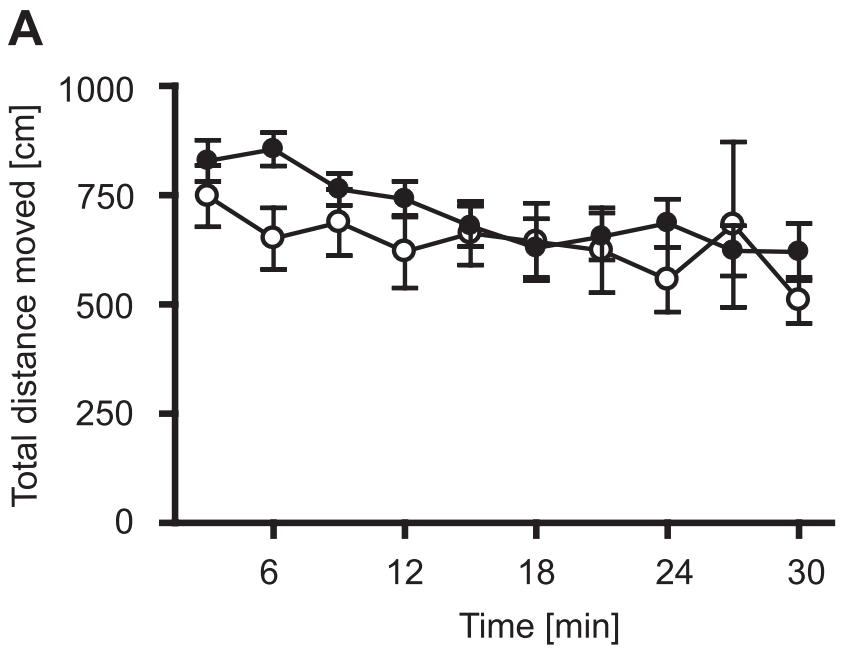

B

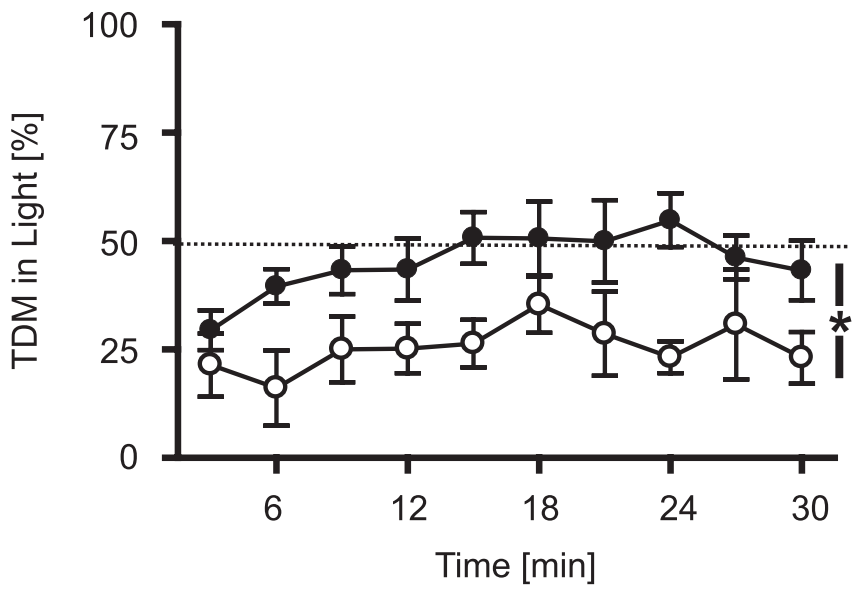

Figure 2. Light- dark test. To assess consequences of TRPV1 deficiency on anxiety-related behavior, we tested TRPV1-K0 and TRPV1-WT in a light-dark test for $30 \mathrm{~min} . A$, There were no differences between TRPV1-KO (filled circles; $n=5$ ) and TRPV1-WT littermates (open circles; $n=7$ ) in the total distance moved. $\boldsymbol{B}$, As shown by the distance moved in the brightly lit compartment normalized to the total distance moved (TDM), TRPV1-K0 explored the lit compartment significantly more than TRPV1-WT. Data were analyzed in 3 min intervals. ${ }^{*} p<0.05$.

the time spent in the light compartment revealed essentially the same results (data and statistics not shown).

\section{Elevated plus maze}

To confirm the anxiolytic effect of TRPV1 ablation observed in the light-dark test in an independent paradigm, we tested a new batch of TRPV1-KO and TRPV1-WT on the elevated plus-maze. TRPV1-KO spent more time on the open arms $(37.0 \pm 12.5 \%)$ than TRPV1-WT $\left(17.3 \pm 4.5 \%\right.$; $t_{(18)}=1.81 ; p=0.043$, onetailed) (Fig. 3A). Moreover, TRPV1-KO made significantly more entries into the open arms than their WT littermates $\left(t_{(18)}=2.70\right.$; $p=0.016$ ) (Fig. $3 B$ ). The total number of entries, in contrast, did not differ between the two genotypes (TRPV1-KO, $21.4 \pm 4.8$; TRPV1-WT, $\left.20.8 \pm 2.3 ; t_{(18)}=0.14 ; p=0.89\right)$, thus corroborating our previous observation of unaltered locomotion in TRPV1-KO.

\section{Auditory fear conditioning}

To look for the role of TRPV1 in acquisition and expression of auditory-cued conditioned fear, we subjected TRPV1-WT and TRPV1-KO to an auditory fear conditioning procedure, in which
A

Time open arms

B

Entries open arms
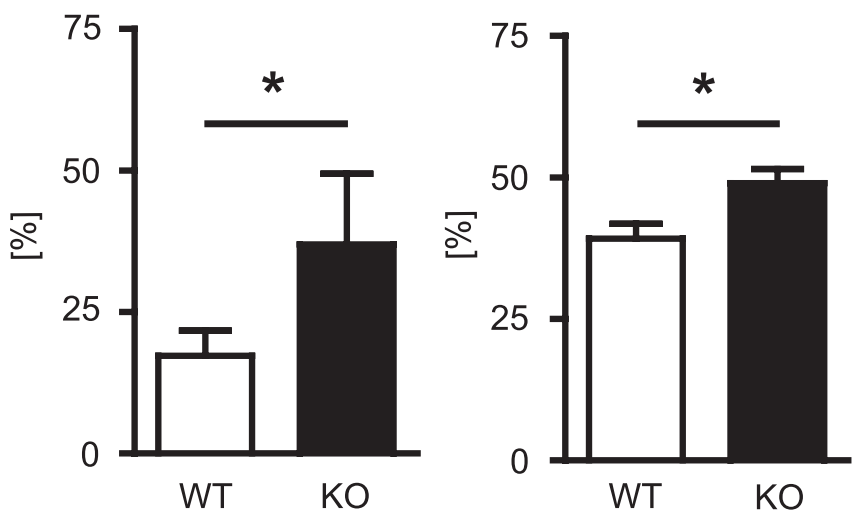

Figure 3. Elevated plus maze. To confirm the anxiolytic-like effect of TRPV1 ablation TRPV1-KO (black bars; $n=7$ ) and TRPV1-WT (white bars; $n=13$ ) were tested on the elevated plus maze. Compared with their WT littermate controls, TRPV1-K0 spent significantly more time on open arms $(\boldsymbol{A})$ and made significantly more entries into the open arms $(\boldsymbol{B})$, normalized to the total time and number of arm entries, respectively. ${ }^{*} p<0.05$.
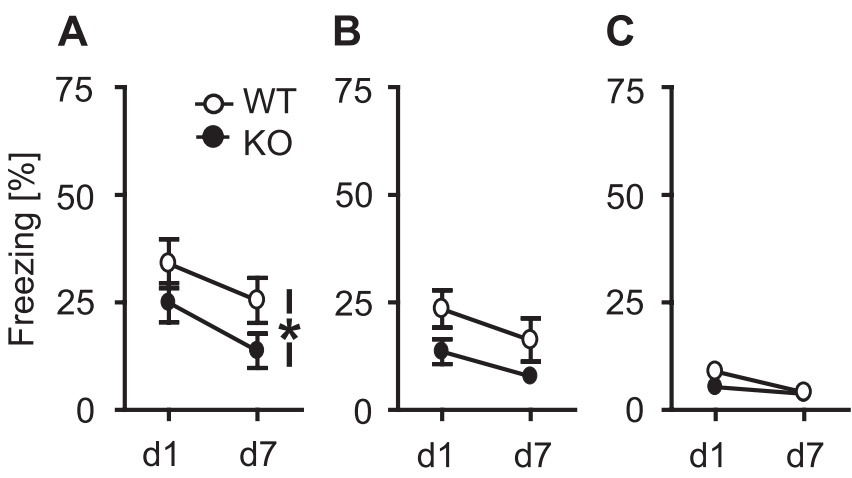

Figure 4. Conditioned, sensitized, and unconditioned fear responses to a tone. $A$, Freezing response to a tone $1 \mathrm{~d}(\mathrm{~d} 1)$ and $7 \mathrm{~d}(\mathrm{~d}$ ) after auditory fear conditioning. TRPV1-K0 (filled circles; $n=11$ ) froze generally less to the tone than TRPV1-WT (open circles; $n=17 ; p<0.05$ ). $\boldsymbol{B}$, Freezing response to a tone $1 \mathrm{~d}(\mathrm{~d} 1)$ and $7 \mathrm{~d}(\mathrm{~d} 7)$ after stress sensitization with three inescapable footshocks. Again, TRPV1-KO (filled circles; $n=18$ ) froze generally less to the tone than TRPV1-WT (open circles; $n=19 ; p=0.054$ ). C, Naive TRPV1-KO (filled circles; $n=12$ ) and TRPV1-WT (open circles; $n=12$ ) showed a similar unconditioned freezing response to a loud tone (95 dB SPL) presented two times to the animals (d1, d7).

a tone coterminated with a single $0.7 \mathrm{~mA}$ footshock. Mice were reexposed to the tone 1 and $7 \mathrm{~d}$ later. If the development of the freezing response from the first to the second tone presentation was considered, there was a significant effect of genotype $\left(F_{(1,26)}=\right.$ $4.3, p<0.05)$ and day $\left(F_{(1,26)}=18.3, p<0.001\right)$ but no significant genotype $\times$ day interaction $\left(F_{(1,26)}=0.33, p=0.573\right)$ (Fig. $4 A$ ), indicating that TRPV1-KO froze generally less to the tone than TRPV1-WT, independently of the test day and with comparable extinction of the fear response. The freezing response of the animals shown during the $3 \mathrm{~min}$ preceding tone presentation (day $1,12.0 \pm 2.8 \%$ for TRPV1-KO vs $9.9 \pm 2.7 \%$ for TRPV1$\mathrm{WT} ; t_{(20)}=0.51 ; p=0.62$ ) was far less pronounced than freezing to the tone, thus indicating that both genotypes learned the toneshock association.

\section{Stress sensitization}

Recently, we could show that both associative and nonassociative memory processes determine the freezing response of mice after auditory fear conditioning (Kamprath and Wotjak, 
2004). To assess whether TRPV1 is involved in non-associative rather than in associative memory processes, we subjected a new batch of mice to a stress sensitization procedure, which lowers the fear threshold of the animals in a manner that subsequently presented potentially fear-eliciting stimuli (such as a tone) may trigger a fear response (Kamprath and Wotjak, 2004). Both TRPV1-KO and TRPV1-WT were exposed to one or three inescapable and unsignaled $0.7 \mathrm{~mA}$ footshocks and exposed to a tone 1 and $7 \mathrm{~d}$ later. After sensitization with a single footshock, there were no differences in the freezing response to the tone between TRPV1-KO and TRPV1-WT (day 1, $9.6 \pm 2.5$ vs $12.7 \pm 2.3 \%$; $\left.t_{(22)}=0.93 ; p=0.364\right)$. After sensitization with three footshocks, both genotypes showed a similar decrease in freezing from day 1 to day 7 (day, $F_{(1,35)}=5.7, p=0.022$; genotype $\times$ day, $F_{(1,35)}=$ $0.8, p=0.782)$, indicating a similar habituation of the fear response. However, TRPV1-KO consistently showed less freezing to the tone than TRPV1-WT (genotype, $F_{(1,35)}=4.0, p=0.054$ ) (Fig. $4 B$ ). Importantly, the freezing response of both genotypes shown during the $3 \mathrm{~min}$ before tone presentation were significantly smaller than shown during tone presentation (TRPV1$\mathrm{KO}, 6.0 \pm 1.4 \%$; TRPV1-WT, $6.0 \pm 1.3 \%$ ), with no differences between the two genotypes $\left(t_{(36)}=0.02 ; p=0.98\right)$. We conclude from these data that (1) freezing to the tone indeed reflects sensitized fear rather than context generalization and thus (2) the differences in freezing to the tone between TRPV1-KO and TRPV1-WT cannot be explained by differences in contextual fear memory. Moreover, (3) TRPV1 seems to be implicated in nonassociative memory processes after strong sensitization procedures.

\section{Pain threshold}

Concerning the role of the TRPV1 channel as a peripheral receptor for nociception, alterations in perception of the electric footshock might explain why TRPV1-KO showed less freezing after both associative (compare with Fig. $4 A$ ) and non-associative learning tasks (compare with Fig. $4 B$ ). Therefore, we assessed in naive TRPV1-KO and TRPV1-WT the individual thresholds of the current intensities necessary for the induction of discomfort and pain. However, there were no statistically significant differences between TRPV1-KO and TRPV1-WT in neither threshold of discomfort (TRPV1-WT, 0.19 $\pm 0.14 \mathrm{~mA}$; TRPV1-KO, $0.18 \pm$ $\left.0.08 \mathrm{~mA} ; t_{(22)}=0.38 ; p=0.71\right)$ nor the threshold of pain (TRPV1-WT, $0.29 \pm 0.23 \mathrm{~mA}$; TRPV1-KO, $0.27 \pm 0.21 \mathrm{~mA}$; $\left.t_{(22)}=0.65 ; p=0.52\right)$.

\section{Unconditioned freezing to a tone}

There was still the option that TRPV1 deficiency altered the perception of tones and, in consequence, the behavioral response to it. Therefore, we exposed naive TRPV1-KO and TRPV1-WT to a loud tone at days 1 and 7. Under these circumstances, no significant differences could be observed between the two genotypes (genotype, $F_{(1,22)}=1.1, p=0.305$; genotype $\times$ day, $F_{(1,22)}=1.6$, $p=0.219)($ Fig. $4 C)$.

\section{DPOAEs and ABRs}

Bearing in mind that immunohistochemical studies localized TRPV1 in the organ of Corti (Zheng et al., 2003) and that analysis of freezing responses of naive mice to loud tones might have been confounded by floor effects (compare with Fig. 4C), we additionally analyzed DPOAEs and ABRs of TRPV1-KO and TRPV1-WT. DPOAEs clearly depended on the frequency tested (frequency, $\left.F_{(3.6,39.6)}=22.03, p<0.001\right)$. There were no significant differences in DPOAE threshold and hence in mechanical sensitivity of

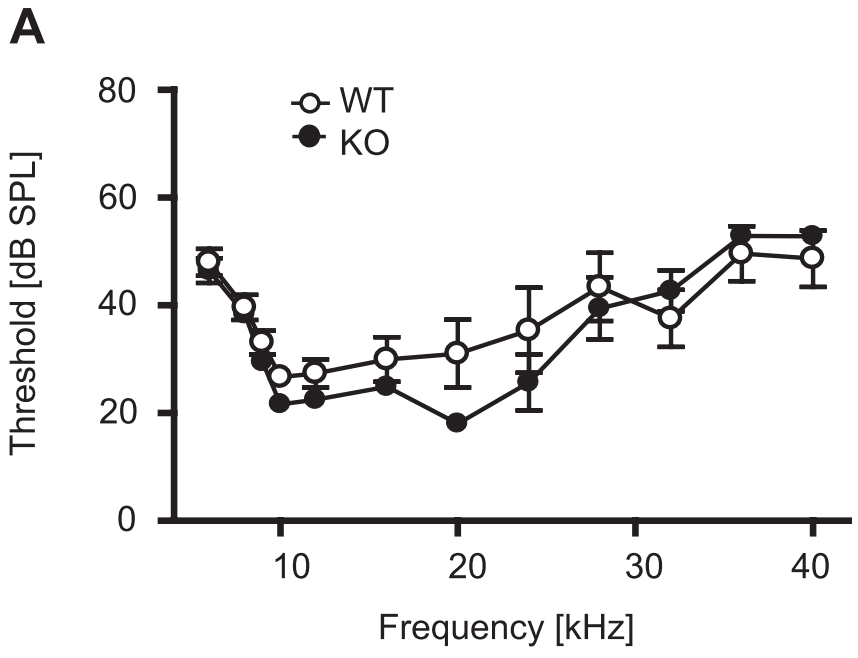

B

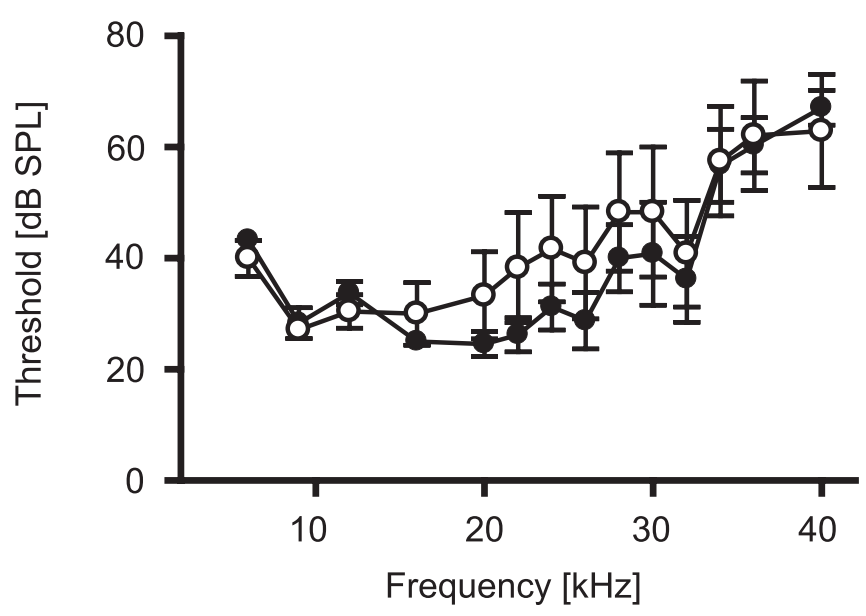

Figure 5. Physiological correlates of tone perception. Measurements of distortion-product otoacoustic emissions $(\boldsymbol{A})$ and auditory brainstem responses $(\boldsymbol{B})$ in anesthetized mice failed to reveal significant differences in tone perception between TRPV1-K0 (filled circles; $n=6$ each) and TRPV1-WT (open circles; $n=5-7$ ), although a shift in the minimum of the threshold could be observed from $9 \mathrm{kHz}$ in TRPV1-WT to $20 \mathrm{kHz}$ in TRPV1-K0.

the cochlea between the genotypes observable (genotype, $F_{(1,11)}=$ $0.30, p=0.597$; genotype $\times$ frequency, $F_{(3.6,39.6)}=1.62, p=$ 0.194 ) (Fig. $5 A$ ). On closer examination at the frequency used for auditory fear conditioning, sensitization, and assessment of unconditioned fear (i.e., $9 \mathrm{kHz}$ ), no significant difference could be observed between TRPV1-KO and TRPV1-WT $\left(t_{(11)}=1.26 ; p=\right.$ $0.23)$. However, the minimum of DPOAE threshold differed between the two genotypes (TRPV1-KO, $20 \mathrm{kHz}$; TRPV1-WT, 10 $\mathrm{kHz}$ ).

The ABR threshold curve failed to show differences between the two genotypes over the range of frequencies tested (genotype, $F_{(1,9)}=0.59, p=0.461$; genotype $\times$ frequency, $F_{(2.63,117)}=1.48$, $p=0.247$ ) (Fig. $5 B$ ). Again, the minimum of ABR threshold differed between the two genotypes (TRPV1-KO, $20 \mathrm{kHz}$; TRPV1-WT, $9 \mathrm{kHz}$ ). Altogether, DPOAE and ABR measurements confirmed normal tone perception in TRPV1-KO.

\section{Contextual fear memory}

To study the role of TRPV1 for hippocampus-dependent learning, we measured the retention of contextual fear memory in mice that had undergone auditory fear conditioning procedures 


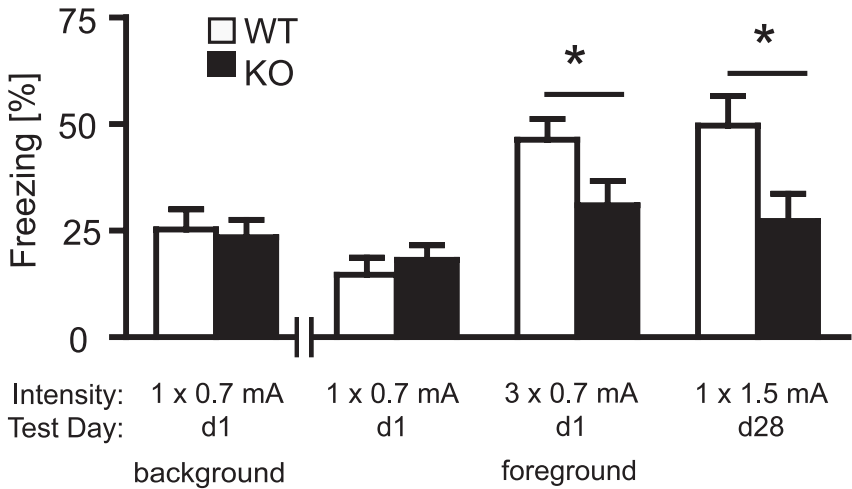

Figure 6. Contextual fear memory. There were no significant differences in the freezing response to the conditioning context between TRPV1-WT (open bars) and TRPV1-KO (filled bars), neither $1 \mathrm{~d}$ after auditory fear conditioning (i.e., background contextual conditioning; $n=11 / 17$ ) nor $1 \mathrm{~d}$ after sensitization (i.e., foreground contextual conditioning; $n=12 / 12$ ) with a single $0.7 \mathrm{~mA}$ footshock. In contrast, TRPV1-KO $(n=18)$ showed significantly less contextual fear than TRPV1-WT ( $n=21$ ) if assessed $1 \mathrm{~d}$ after stress sensitization with three 0.7 $\mathrm{mA}$ footshocks. The same was the case if TRPV1-KO $(n=7)$ and TRPV1-WT $(n=13)$ were tested $28 \mathrm{~d}$ after stress sensitization with a single $1.5 \mathrm{~mA}$ footshock. ${ }^{*} p<0.05$.

(i.e., background contextual conditioning) or stress sensitization procedures (i.e., foreground contextual conditioning) with different intensities. There were no differences between the two genotypes in the freezing response to the conditioning context at neither $1 \mathrm{~d}$ after background $\left(t_{(26)}=0.28 ; p=0.779\right)$ nor $1 \mathrm{~d}$ after foreground contextual conditioning $\left(t_{(22)}=0.67 ; p=0.510\right)$ with a single $0.7 \mathrm{~mA}$ shock (Fig. 6). In contrast, TRPV1-KO showed significantly less contextual fear than TRPV1-WT $1 \mathrm{~d}$ after foreground contextual conditioning with three $0.7 \mathrm{~mA}$ footshocks $\left(t_{(37)}=2.1 ; p<0.05\right)$, as well as $28 \mathrm{~d}$ after foreground contextual conditioning with a single $1.5 \mathrm{~mA}$ footshock $\left(t_{(18)}=\right.$ $2.1 ; p<0.05)$ (Fig. 6).

\section{Electrophysiological experiments}

To assess whether impairments in contextual fear memory coincided with alterations in synaptic plasticity in the CA1 region of the dorsal hippocampus, we studied paired-pulse facilitation and LTP in the Schaffer collateral-commissural pathway in acute brain slices from TRPV1-KO and TRPV1-WT. Analysis of paired-pulse facilitation failed to reveal significant differences between the two genotypes over a range of intervals between 20 and $300 \mathrm{~ms}$ (statistics not shown) (Fig. 7A). After induction of LTP by HFS, however, TRPV1-KO mice showed a significantly weaker LTP than TRPV1-WT littermates for at least 60 min after $\operatorname{HFS}\left(t_{(10)}=2.49 ; p<0.05\right)$ (Fig. $\left.7 B\right)$.

\section{Discussion}

This study demonstrates for the first time a crucial role of TRPV1 in regulating anxiety-related behaviors, conditioned fear, as well as long-term potentiation of EPSPs in the hippocampus.

In a first set of experiments, we assessed anxiety-related behavior in the light-dark test and on the elevated plus maze. Both paradigms are used for measuring state anxiety that is based on the conflict between exploration of novel environments and the avoidance of potentially dangerous situations (Hogg, 1996; Rodgers and Dalvi, 1997; Hascoet et al., 2001; Millan et al., 2003; de Sousa et al., 2006). TRPV1-KO much faster adapted to the aversive light compartment, spent more time in the light compartment in the light-dark test, and explored the open arms of the elevated plus maze more intensively than their wild-type littermates, indicating that they are less anxious. Taking into con-

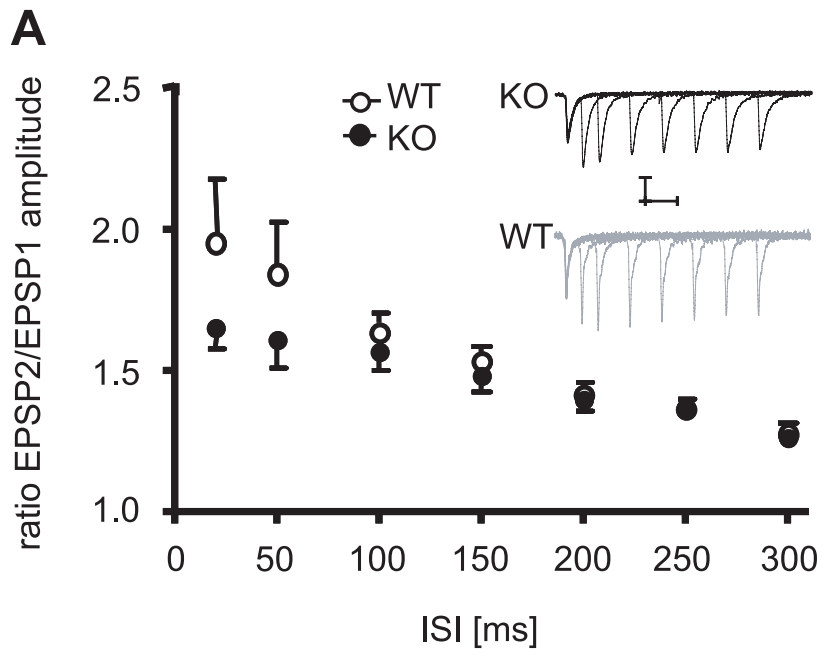

B

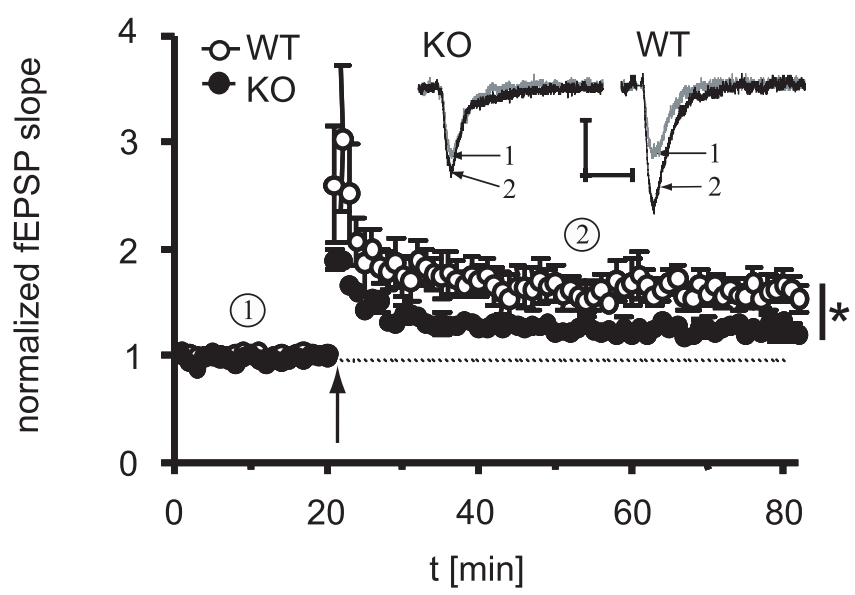

Figure 7. Short-term and long-term plasticity in CA1. A, There were no significant differences in paired-pulse facilitation of fEPSPs between TRPV1-KO (filled circles) and TRPV1-WT (open circles) over a range of interstimulus intervals (ISI) between 20 and $300 \mathrm{~ms}$. Insets show sample responses taken during paired-pulse stimulation for TRPV1-KO (black) and TRPV1-WT (gray). Calibration: $0.25 \mathrm{mV}, 10 \mathrm{~ms}$. B, Time course of field EPSPs evoked by test pulses $(0.033$ $\mathrm{Hz}, 20 \mu \mathrm{s})$ before and after an HFS (100 Hz/1 s, arrow). After induction of LTP, TRPV1-K0 showed a significantly weaker LTP for at least $60 \mathrm{~min}$ after HFS. Insets show sample responses taken before (gray, 1) and after (black, 2) HFS for TRPV1-K0 and TRPV1-WT. Calibration: $0.5 \mathrm{mV}$, $10 \mathrm{~ms}$. For each genotype, a total of six brain slices obtained from four mice were analyzed. ${ }^{*} p<0.05$.

sideration that (1) activation of TRPV1 by exogenous ligands may alter locomotion (Di Marzo et al., 2001b), which, in turn, is known (2) to confound the interpretation of the behavioral phenotype observed in anxiety tests (Dawson and Tricklebank, 1995), we confirmed in an open field and by test-specific parameters that the anxiolytic-related phenotype of TRPV1 ablation was unrelated to alterations in locomotion.

In a second set of experiments, we assessed the consequences of TRPV1 ablation on conditioned fear to an unimodal cue (tone). TRPV1-KO showed less freezing to the tone after auditory fear conditioning but a similar decrease in freezing from a first to a second tone presentation, indicating that TRPV1 is involved in acquisition and/or expression of conditioned fear but not in its extinction. Control experiments assessing behavioral (freezing response of naive mice to a loud tone) and physiological parameters (measurement of distortion-product otoacoustic emissions and of auditory brainstem responses) ruled out that the reduc- 
tion in conditioned fear simply relates to altered tone perception. TRPV1-KO showed also less freezing to a tone after stress sensitization with unsignaled footshocks, thus rendering it likely that TRPV1 is involved in acquisition and/or expression of nonassociative rather than associative components of auditory-cued conditioned fear (Kamprath and Wotjak, 2004). The differences in conditioned and sensitized fear are unlikely to result from different perception and processing of the footshock because both TRPV1-KO and TRPV1-WT showed the same pain sensitivity to a footshock of rising intensity. Previous studies reporting TRPV1-KO to be less sensitive to heat than TRPV1-WT (Caterina et al., 2000). This reputed discrepancy might be explained by the fact that TRPV1 is expressed primarily in small- to mediumdiameter primary sensory neurons such as $\mathrm{C}$ fibers (Tominaga et al., 1998), which become activated by noxious thermal and chemical stimuli but not by electric shocks.

In a third set of experiments, we could demonstrate that TRPV1-KO were impaired in acquisition and/or expression of contextual fear memory. The effects of TRPV1 ablation became evident after strong conditioning procedures only and persisted for at least 1 month. Strikingly, whereas auditory fear conditioning led to a weaker fear response to the tone in TRPV1-KO compared with TRPV1-WT, the same animals showed similar contextual fear memory. This observation precludes that any differences in innate fear and anxiety account for the differences in conditioned contextual fear. Moreover, it suggests that TRPV1 is differentially involved in auditory-cued and in contextual fear memory. The latter requires an intact hippocampal formation in addition to the involvement of the basolateral amygdala complex (Kim and Fanselow, 1992; Rudy et al., 2004). Pharmacological blockade of NMDA receptors or local protein synthesis within the dorsal hippocampus significantly impaired acquisition and consolidation of contextual fear memory in a background conditioning task (Stiedl et al., 2000). Recently, we extended this observation to foreground conditioning tasks with C57BL/6N mice (i.e., the background strain of TRPV1 mutants). We could demonstrate that pharmacological blockade of NMDA receptors within the dorsal hippocampus before stress sensitization with a single $1.5 \mathrm{~mA}$ shock impaired contextual fear memory as assessed 28 d later (Siegmund and Wotjak, 2006). Because untreated TRPV1-KO showed less contextual fear memory than TRPV1-WT under otherwise similar experimental conditions (Fig. 6), we looked for physiological correlates of the impaired contextual learning in the dorsal hippocampus of the animals. We could induce a stable LTP in the CA1 region of TRPV1-KO that was, however, less pronounced than in TRPV1-WT. It is tempting to speculate that this reduction in LTP corresponds to the inability of TRPV1-KO to form a stronger contextual fear memory after stronger conditioning procedures.

As for all studies using genetically engineered mouse mutants with constitutively arrested expression of a certain gene of interest, the data obtained in TRPV1-KO have to be interpreted with caution (Gerlai, 1996; Crusio, 2004). Both compensatory processes and differences in the genetic background of the flanking regions of the mutation site may contribute to the phenotype observed. Nevertheless, we consider the option of compensatory mechanisms to be of minor importance, because TRPV1-KO differed from their wild-type littermates under aversive conditions only (e.g., light-dark and elevated plus-maze test but not openfield test; altered contextual fear memory after strong conditioning protocols only). Such alterations do not occur under the standardized housing conditions established in our institute. Under these circumstances, it is questionable whether TRPV1 gets suf- ficiently activated throughout development, which minimizes the risk of compensatory processes in TRPV1-KO mice. Therefore, we conclude from our data that, in wild-type mice, TRPV1 promotes innate fear and anxiety, non-associative memory components of auditory-cued fear memories, acquisition and/or expression of contextual fear memories after strong conditioning procedures, and LTP in the dorsal hippocampus. These effects are diametrically opposite to those ascribed to an activation of $\mathrm{CB}_{1}$, which may reduce innate fear and anxiety (Viveros et al., 2005; Wotjak, 2005), weaken behavioral consequences of nonassociative memory components on expression of conditioned fear (Kamprath et al., 2006), and cause a reduction in LTP (Bohme et al., 2000; Slanina et al., 2005). In line with these arguments, TRPV1-mediated effects of anandamide in the hippocampus turned out to be opposite to those induced via $\mathrm{CB}_{1}$ by 2-arachidonylglycerol (Al-Hayani et al., 2001). In addition, whereas activation of TRPV1 promotes excitatory facilitation of synaptic transmission (Marinelli et al., 2002, 2003), activation of $\mathrm{CB}_{1}$ leads to a reduction in presynaptic calcium levels and, thus, to a reduction of synaptic transmission (for review, see Chevaleyre et al., 2006). Some fatty acid derivatives such as anandamide or $N$-arachidonyldopamine bind and activate TRPV1 and $\mathrm{CB}_{1}$ receptors equally well and can, thus, be regarded as both endovanilloids and endocannabinoids (van der Stelt and Di Marzo, 2004; Marinelli et al., 2006). Consequently, activation of TRPV1 and $\mathrm{CB}_{1}$ by their endogenous ligands seems to provide antagonistic principles that in concert contribute to well balanced emotional responses and synaptic plasticity, similar to their effects in the substantia nigra pars compacta (Marinelli et al., 2006). Taking this into account, the behavioral phenotype observed after genetic ablation or pharmacological blockade of $\mathrm{CB}_{1}$ and TRPV1, respectively, may comprise the sum of both prevention of anandamide action at the one receptor and unrestricted action of anandamide at the other receptor. Conversely, potentiation of endocannabinoid signaling, for instance by blocking anandamide reuptake and degradation (Di Marzo et al., 2004), may at the same time decrease fear and anxiety in a $\mathrm{CB}_{1}$-dependent manner (for review, see Viveros et al., 2005; Wotjak, 2005) but promote fear and anxiety in a TRPV1-dependent manner (present study). This has to be considered if the endocannabinoid system is going to be exploited as therapeutic target for the pharmacological treatment of human psychiatric disorders (Di Marzo et al., 2004).

\section{References}

Al-Hayani A, Wease KN, Ross RA, Pertwee RG, Davies SN (2001) The endogenous cannabinoid anandamide activates vanilloid receptors in the rat hippocampal slice. Neuropharmacology 41:1000-1005.

Bohme GA, Laville M, Ledent C, Parmentier M, Imperato A (2000) Enhanced long-term potentiation in mice lacking cannabinoid CB1 receptors. Neuroscience 95:5-7.

Caterina MJ, Schumacher MA, Tominaga M, Rosen TA, Levine JD, Julius D (1997) The capsaicin receptor: a heat-activated ion channel in the pain pathway. Nature 389:816-824.

Caterina MJ, Leffler A, Malmberg AB, Martin WJ, Trafton J, Petersen-Zeitz KR, Koltzenburg M, Basbaum AI, Julius D (2000) Impaired nociception and pain sensation in mice lacking the capsaicin receptor. Science 288:306-313.

Chevaleyre V, Takahashi KA, Castillo PE (2006) Endocannabinoidmediated synaptic plasticity in the CNS. Annu Rev Neurosci 29:37-76.

Cristino L, De Petrocellis L, Pryce G, Baker D, Guglielmotti V, Di Marzo V (2006) Immunohistochemical localization of cannabinoid type 1 and vanilloid transient receptor potential vanilloid type 1 receptors in the mouse brain. Neuroscience 139:1405-1415.

Crusio WE (2004) Flanking gene and genetic background problems in genetically manipulated mice. Biol Psychiatry 56:381-385. 
Dawson GR, Tricklebank MD (1995) Use of the elevated plus-maze in the search for novel anxiolytic agents. Trends Pharmacol Sci 16:33-36.

De Petrocellis L, Di Marzo V (2005) Lipids as regulators of the activity of transient receptor potential type V1 (TRPV1) channels. Life Sci 77:1651-1666.

de Sousa N, Almeida OF, Wotjak CT (2006) A hitchhiker's guide to behavioral analysis in laboratory rodents. Genes Brain Behav 5 [Suppl 2]:5-24.

Di Marzo V, Bisogno T, De Petrocellis L (2001a) Anandamide: some like it hot. Trends Pharmacol Sci 22:346-349.

Di Marzo V, Lastres-Becker I, Bisogno T, De Petrocellis L, Milone A, Davis JB, Fernandez-Ruiz JJ (2001b) Hypolocomotor effects in rats of capsaicin and two long chain capsaicin homologues. Eur J Pharmacol 420:123-131.

Di Marzo V, Bifulco M, De Petrocellis L (2004) The endocannabinoid system and its therapeutic exploitation. Nat Rev Drug Discov 3:771-784.

Freund TF, Katona I, Piomelli D (2003) Role of endogenous cannabinoids in synaptic signaling. Physiol Rev 83:1017-1066.

Gerlai R (1996) Gene-targeting studies of mammalian behavior: is it the mutation or the background genotype? Trends Neurosci 19:271.

Hascoet M, Bourin M, Dhonnchadha BAN (2001) The mouse light-dark paradigm: a review. Prog Neuropsychopharmacol Biol Psychiatry 25:141-166.

Hogg S (1996) A review of the validity and variability of the elevated plusmaze as an animal model of anxiety. Pharmacol Biochem Behav 54:21-30.

Huang SM, Bisogno T, Trevisani M, Al Hayani A, De Petrocellis L, Fezza F, Tognetto M, Petros TJ, Krey JF, Chu CJ, Miller JD, Davies SN, Geppetti P, Walker JM, Di Marzo V (2002) An endogenous capsaicin-like substance with high potency at recombinant and native vanilloid VR1 receptors. Proc Natl Acad Sci USA 99:8400-8405.

Kamprath K, Wotjak CT (2004) Nonassociative learning processes determine expression and extinction of conditioned fear in mice. Learn Mem 11:770-786.

Kamprath K, Marsicano G, Tang J, Monory K, Bisogno T, Di Marzo V, Lutz B, Wotjak CT (2006) Cannabinoid $\mathrm{CB}_{1}$ receptor mediates fear extinction via habituation-like processes. J Neurosci 26:6677-6686.

Kim JJ, Fanselow MS (1992) Modality-specific retrograde-amnesia of fear. Science 256:675-677.

Kromer SA, Kessler MS, Milfay D, Birg IN, Bunck M, Czibere L, Panhuysen M, Putz B, Deussing JM, Holsboer F, Landgraf R, Turck CW (2005) Identification of glyoxalase-I as a protein marker in a mouse model of extremes in trait anxiety. J Neurosci 25:4375-4384.

Mackie K, Hille B (1992) Cannabinoids inhibit N-type calcium channels in neuroblastoma glioma-cells. Proc Natl Acad Sci USA 89:3825-3829.

Marinelli S, Vaughan CW, Christie MJ, Connor M (2002) Capsaicin activation of glutamatergic synaptic transmission in the rat locus coeruleus in vitro. J Physiol (Lond) 543:531-540.

Marinelli S, Di Marzo V, Berretta N, Matias I, Maccarrone M, Bernardi G, Mercuri NB (2003) Presynaptic facilitation of glutamatergic synapses to dopaminergic neurons of the rat substantia nigra by endogenous stimulation of vanilloid receptors. J Neurosci 23:3136-3144.

Marinelli S, Di Marzo V, Florenzano F, Fezza F, Viscomi MT, van der Stelt M, Bernardi G, Molinari M, Maccarrone M, Mercuri NB (2006) $\mathrm{N}$-Arachidonoyl-dopamine tunes synaptic transmission onto dopaminergic neurons by activating both cannabinoid and vanilloid receptors. Neuropsychopharmacology, in press.

Massa F, Sibaev A, Marsicano G, Blaudzun H, Storr M, Lutz B (2006) Vanilloid receptor (TRPV1)-deficient mice show increased susceptibility to dinitrobenzene sulfonic acid induced colitis. J Mol Med 84:142-146.

Mezey E, Toth ZE, Cortright DN, Arzubi MK, Krause JE, Elde R, Guo A, Blumberg PM, Szallasi A (2000) Distribution of mRNA for vanilloid receptor subtype 1 (VR1), and VR1-like immunoreactivity, in the central nervous system of the rat and human. Proc Natl Acad Sci USA 97:3655-3660.

Millan MJ, Veiga S, Girardon S, Brocco M (2003) Blockade of serotonin 5-HT1B and 5-HT2A receptors suppresses the induction of locomotor activity by $5-\mathrm{HT}$ reuptake inhibitors, citalopram and fluvoxamine, in
NMRI mice exposed to a novel environment: a comparison to other 5-HT receptor subtypes. Psychopharmacology 168:397-409.

Piomelli D (2003) The molecular logic of endocannabinoid signalling. Nat Rev Neurosci 4:873-884.

Roberts JC, Davis JB, Benham CD (2004) $\left[{ }^{3} \mathrm{H}\right]$ resiniferatoxin autoradiography in the CNS of wild-type and TRPV1 null mice defines TRPV1 (VR-1) protein distribution. Brain Res 995:176-183.

Rodgers RJ, Dalvi A (1997) Anxiety, defence and the elevated plus-maze. Neurosci Biobehav Rev 21:801-810.

Rudy JW, Huff NC, Matus-Amat P (2004) Understanding contextual fear conditioning: insights from a two-process model. Neurosci Biobehav Rev 28:675-685.

Siegmund A, Wotjak CT (2007) Hyperarousal does not depend on traumarelated contextual memory in an animal model of Posttraumatic Stress Disorder. Physiol Behav 90:103-107.

Siegmund A, Langnaese K, Wotjak CT (2005) Differences in extinction of conditioned fear in C57BL/6 substrains are unrelated to expression of alpha-synuclein. Behav Brain Res 157:291-298.

Simon W, Hapfelmeier G, Kochs E, Zieglgansberger W, Rammes G (2001) Isoflurane blocks synaptic plasticity in the mouse hippocampus. Anesthesiology 94:1058-1065.

Slanina KA, Roberto M, Schweitzer P (2005) Endocannabinoids restrict hippocampal long-term potentiation via CB1. Neuropharmacology 49:660-668.

Stiedl O, Birkenfeld K, Palve M, Spiess J (2000) Impairment of conditioned contextual fear of C57BL/6J mice by intracerebral injections of the NMDA receptor antagonist APV. Behav Brain Res 116:157-168.

Szallasi A, Appendino G (2004) Vanilloid receptor TRPV1 antagonists as the next generation of painkillers. Are we putting the cart before the horse? J Med Chem 47:2717-2723.

Szallasi A, Blumberg PM (1999) Vanilloid (capsaicin) receptors and mechanisms. Pharmacol Rev 51:159-211.

Tominaga M, Caterina MJ, Malmberg AB, Rosen TA, Gilbert H, Skinner K, Raumann BE, Basbaum AI, Julius D (1998) The cloned capsaicin receptor integrates multiple pain-producing stimuli. Neuron 21:531-543.

Toth A, Boczan J, Kedei N, Lizanecz E, Bagi Z, Papp Z, Edes I, Csiba L, Blumberg PM (2005) Expression and distribution of vanilloid receptor 1 (TRPV1) in the adult rat brain. Mol Brain Res 135:162-168.

Valverde O, Karsak M, Zimmer A (2005) Analysis of the endocannabinoid system by using CB1 cannabinoid receptor knockout mice. Handb Exp Pharmacol (168):117-145.

van der Stelt M, Di Marzo V (2004) Endovanilloids: putative endogenous ligands of transient receptor potential vanilloid 1 channels. Eur J Biochem 271:1827-1834.

van der Stelt M, Trevisani M, Vellani V, De Petrocellis L, Moriello AS, Campi B, McNaughton P, Geppetti P, Di Marzo V (2005) Anandamide acts as an intracellular messenger amplifying $\mathrm{Ca}^{2+}$ influx via TRPV1 channels. EMBO J 24:3517-3518.

Viveros MP, Marco EM, File SE (2005) Endocannabinoid system and stress and anxiety responses. Pharmacol Biochem Behav 81:331-342.

Wilson RI, Nicoll RA (2002) Neuroscience: endocannabinoid signaling in the brain. Science 296:678-682.

Wittekindt A, Drexl M, Kossl M (2005) Cochlear sensitivity in the lesser spear-nosed bat, Phyllostomus discolor. J Comp Physiol A Neuroethol Sens Neural Behav Physiol Neuroethol Sens Neural Behav Physiol 191:31-36.

Wotjak CT (2005) Role of endogenous cannabinoids in cognition and emotionality. Mini Rev Med Chem 5:659-670.

Zheng JF, Dai CF, Steyger PS, Kim Y, Vass Z, Ren TY, Nuttall AL (2003) Vanilloid receptors in hearing: altered cochlear sensitivity by vanilloids and expression of TRPV1 in the organ of Corti. J Neurophysiol 90:444-455.

Zygmunt PM, Petersson J, Andersson DA, Chuang H, Sorgard M, Di Marzo V, Julius D, Hogestatt ED (1999) Vanilloid receptors on sensory nerves mediate the vasodilator action of anandamide. Nature 400:452-457. 